\title{
ESTIMATING THE 2011 LARGEST FLOOD DISCHARGE AT THE KUMANO RIVER USING A 2D DYNAMIC WAVE MODEL AND PARTICLE FILTERS
}

\author{
Yeonsu KIM${ }^{1}$, Yasuto TACHIKAWA 2 , Sunmin $\mathrm{KIM}^{3}$, \\ Michiharu SHIIBA ${ }^{4}$, Seong Jin $\mathrm{NOH}^{1}$, and Takashi MENO ${ }^{1}$, \\ ${ }^{1}$ Student Member of JSCE, Dept. of, Civil and Earth Resources Eng., Kyoto Univ. (Kyoto 615-8540, Japan) \\ ${ }^{2}$ Member of JSCE, Assoc. Prof., Dept. of Civil and Earth Resources Eng., Kyoto Univ. (Kyoto 615-8540, Japan) \\ ${ }^{3}$ Member of JSCE, Lecturer, Dept. of Civil and Earth Resources Eng., Kyoto Univ. (Kyoto 615-8540, Japan) \\ ${ }^{4}$ Member of JSCE, Prof., Dept. of Civil and Earth Resources Eng., Kyoto Univ. (Kyoto 615-8540, Japan)
}

\begin{abstract}
The largest-ever flood event was recorded at the Kumano River in the Kii peninsula of Japan from August 31 to September 4, 2011. Water level data exceeded the observation range in many places except in the Ouga water stage station at downstream. This study aimed to estimate the peak discharge of the event by using the estimation method, which is a $2 \mathrm{D}$ dynamic wave model combined with particle filters, and by considering the water level observed at the Hitari and Ouga stations and a river discharge estimated by a hydrological model. The estimation method was applied to the three historic flood events for quantifying the uncertainties of the Manning roughness coefficient (Manning's $n$ ) of the subject river channel. Based on the optimized range of Manning's $n$, the filtering method was applied to estimate the largest peak discharge of the 2011 flood using the discharge estimated by a hydrological model. The possible range of the largest peak discharge was successfully evaluated through the comparison of the observed flood marks. Finally, a rating curve established by the estimation results at the Ouga station is examined.
\end{abstract}

Key Words: 2D dynamic wave model, particle filters, Kumano River, 2011 flood, rating curve

\section{INTRODUCTION}

From August 31 to September 4, 2011, the largest ever flood event occurred in the Kii peninsula, Japan due to the $12^{\text {th }}$ typhoon in 2011. Although the peak discharge was able to be estimated using a rating curve or a hydrological model ${ }^{1)}$, its accuracy is controversial because of the uncertainties in the rating curve at the Ouga station, and prediction uncertainties of a hydrologic model for the largest flood we have ever experienced. Historic flood events utilized in the hydrologic model calibration ${ }^{1)}$ are all located in the extrapolation ranges in the rating curve.

Prediction uncertainties of discharge come from the various characteristics of the open channel flow such as channel geomorphology, channel roughness, initial and boundary conditions and so on. Considering such factors properly, it makes sense that a hydraulic model and a hydrologic model should be fully utilized to estimate river discharge combined with filtering techniques and all available observed information.

To estimate river discharge using the hydraulic model, one essential prerequisite is the boundary condition such as inflow from the upper reach. The upper boundary inflow is possible to estimate using a hydrologic model; however, the uncertainty included in the estimated boundary inflow should be treated properly with filtering techniques. To consider the uncertainties of the boundary conditions, Tachikawa et $a l^{2)}$ and Kim et $a l^{3)}{ }^{3)}$ introduced particle filters (PFs) into 1-dimensional and 2-dimensional hydraulic models, respectively, and successfully provided reliable river stages and discharges within the uncertain upstream inflow data. In the estimation methods to deal with the uncertainties of the discharge, available information such as water level was used as reference data to evaluate the uncertainties and update the state variables. Kim et al. . $^{3)}$ adopted a 2D hydraulic model to consider the channel geomorphology more precisely, which incorporated reference water level data more effectively than a $1 \mathrm{D}$ model.

Simultaneous estimation of two variables such as channel roughness and upper boundary inflow discharge is a delicate problem because their 


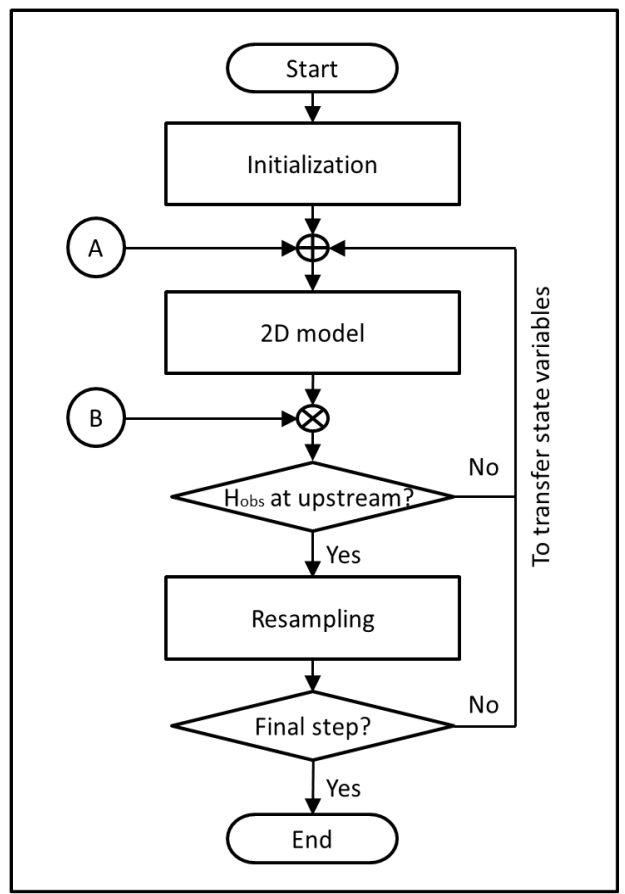

Reading the boundary conditions $\left(Q^{u p}, h^{\text {down }}, n\right)_{1}^{1}$

: Reading the reference data $\left(h^{u p}\right)$

Fig. 1 Flow chart of the estimation process.

combination can be almost unlimited for a given observed water level. Thus Hsu et $a l^{4)}$, Ding et al. ${ }^{5)}$, and Kim et $a l^{6}{ }^{6}$ only focused on one of two factors: either channel roughness or boundary inflow. However, the boundary inflow and the channel roughness should be estimated simultaneously considering that the channel roughness is affected continuously by the evolving channel geomorphology and the vegetation distribution of the flood plain.

In our previous study ${ }^{7)}$, it was shown that boundary inflow and channel roughness were able to be estimated simultaneously in a reasonable range using a 2-D hydraulic model combined with particle filters. Based on several historic flood events, the uncertain ranges of channel roughness can be identified and the most reasonable boundary inflow can be estimated. By utilizing this information, it is possible to estimate the proper river discharge of the following event, even though it has the largest ever flood peak.

In September 2011, the largest flood happened at the Kumano River basin resulting in an exceeded observation range at various water stage stations with the exception of the Ouga station. The rating curve at the Ouga station could have large uncertainties because the observed water level in the 2011 flood far exceeds the applicable range of the existing rating curve. Therefore, this study aimed to estimate the discharge of the flood event in September, 2011 by fully utilizing a 2D hydraulic model, a distributed hydrologic model and filtering techniques with all available information. A sequential uncertainties analysis based on the previous study ${ }^{7}$ is applied first to quantify a proper range of channel roughness of the study river using the events occurring in August, 2003, August, 2004 and September, 2004. Based on the optimized model parameters, a distributed hydrologic model $^{1)}$ and a 2D hydraulic model are fully utilized with limited water level information and flood marks to estimate the discharge of the largest flood in 2011.

\section{APPLICATION PROCESS}

As shown in Fig. 1, the whole process is composed of two parts: a 2D hydraulic model and particle filters. The connector " $\mathrm{A}$ " and " $\mathrm{B}$ " indicate reading boundary conditions and reading reference data, respectively. The basic frame shown in Fig. $\mathbf{1}$ is the method proposed by Kim et al. ${ }^{7)}$, which is used to estimate the spatial distribution of the channel roughness and the upper boundary inflow discharge at the same time. Kim et $a l^{7)}$ applied the method to estimate channel roughness using discharge converted from a rating curve adding noise as the upper boundary condition. At the upper boundary of the channel reach in this subject area, the Hitari station, water level data is observed, although a rating curve is not established. Therefore, the upper boundary inflow discharge was estimated by a distributed hydrological model ${ }^{1)}$ as an alternative.

The initial range of Manning's $n$ is sequentially updated as the process progresses. The analysis process consists of three applications for the different events in August 2003, August 2004, and September 2004, respectively. At the first application for the August 2003 flood, the initial range of Manning's $n$ is set by certain values for the main channel, flood plain, and inundation area. Then, from the second application for the August 2004 flood, the initial range of Manning's $n$ is set by the $90 \%$ interval estimated at the final step of the previous application.

Fig. 1 also shows the process to estimate the discharge of 2011 flood. The estimation method is the same as that applied to the three historic floods. However, the resampling step stops after the upstream water level used as the reference data does not exist due to exceed the observation range. In case of no data as a reference data of the estimation process, the process proceeds without resampling. The distribution of the inflow boundary discharge and Manning's $n$ follow the distribution of the final step result when there is resampling.

For the application of the method to the largest flood in 2011, an upper boundary inflow is used as an averaged hydrograph estimated by a distributed hydrological model with different parameter sets optimized for different events ${ }^{1}$. A noise term is added to the inflow, and it is used for the upper boundary condition. Manning's $n$ is used for the finally estimated value from the third event occurring in 


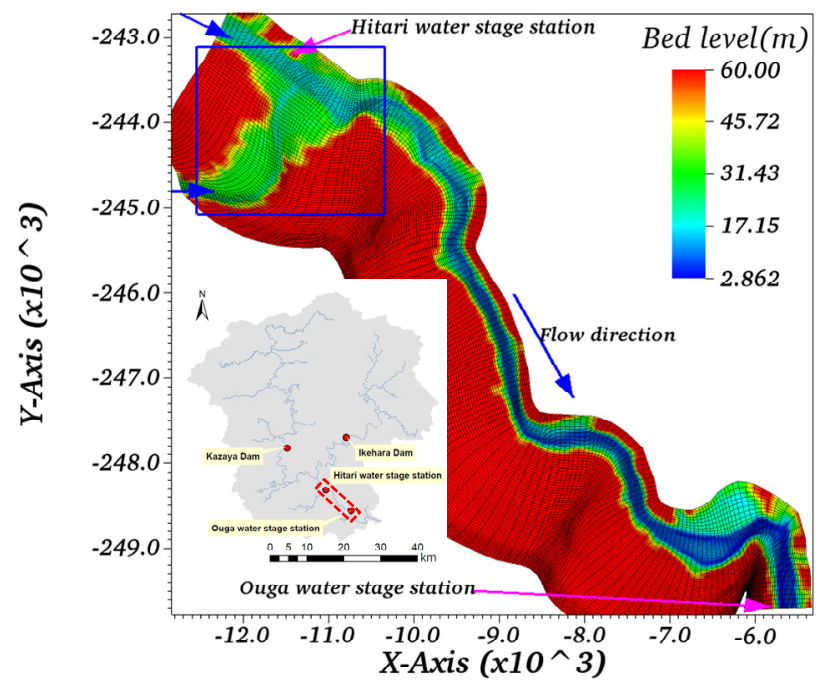

Fig. 2 Study area and calculation domain.

September 2004, which is used for the initial range of the channel roughness to estimate the discharge of the largest event in 2011.

\section{SIMULTANUOUSESTIMATIONOF DISCHARGE AND CHANNEL ROUGHNESS}

\section{(1) Study area}

The study area is the Kumano River located in the Kii peninsula, Japan. The total reach length is about $11 \mathrm{~km}$ from the Hitari water stage station to the Ouga water stage station, which are located at upstream and downstream boundaries, respectively. The calculation domain is composed of 212 longitudinal points and 88 cross sectional points for a 2D hydraulic model (Fig. 2). The channel roughness is classified into three parts: main channel, flood plain, and inundation area. These parts are classified by the aerial photo. As upper boundary inflow conditions, the upstream discharge from the tributary (the Akagi River) and the main channel (the Kumano River) are considered. The lateral inflow to the channel reach is disregarded because the largest volume per second is smaller than $600 \mathrm{~m}^{3} / \mathrm{s}$ even in the largest flood in 2011 as estimated by the distributed hydrologic model.

\section{(2) 2D dynamic wave model}

The 2D dynamic wave model is composed of the continuity equation (Eq. (1)) and the momentum equation (Eq. (2) and (3)). The equations are numerically solved with the Finite Volume Method $(\mathrm{FVM})$ on a structure grid $^{8)}$. The simple first order upwind scheme is utilized for the convection term. The Adams-Bashforth method is introduced for time integration $^{8)}$.

$$
\begin{gathered}
\frac{\partial h}{\partial t}+\frac{\partial M}{\partial x}+\frac{\partial N}{\partial y}=0 \\
\frac{\partial M}{\partial t}+\frac{\partial u M}{\partial x}+\frac{\partial v M}{\partial y}=-g h \frac{\partial Z_{s}}{\partial x}-\frac{\tau_{b x}}{\rho}+\frac{\partial}{\partial x}\left(-\overline{u^{\prime 2}} h\right)+\frac{\partial}{\partial y}\left(-\overline{u^{\prime} v^{\prime} h}\right)
\end{gathered}
$$

$$
\frac{\partial N}{\partial t}+\frac{\partial u N}{\partial x}+\frac{\partial v N}{\partial y}=-g h \frac{\partial Z_{s}}{\partial y}-\frac{\tau_{b y}}{\rho}+\frac{\partial}{\partial x}\left(-\overline{u^{\prime} v^{\prime}} h\right)+\frac{\partial}{\partial y}\left(-\overline{v^{\prime 2}} h\right)
$$

where $h$ is water depth; $Z_{s}$ is water stage; $t$ is time; $u$ and $v$ are depth averaged velocity in $x$ and $y$ direction; $M$ and $N$ denote discharge flux in $x$ and $y$ direction; $\rho$ is density of water; and $\tau_{b x}$ and $\tau_{b y}$ are the bed shear stress in $x$ and $y$ direction.

\section{(3) Particle Filters(PFs)}

PFs perform the sequential Monte Carlo (SMC) estimation based on particle representations of probability densities within Bayesian theorem ${ }^{9}$. The main purpose of PFs is to track a target variable as it evolves over time, typically with a non-Gaussian and multi-modal probability density function ${ }^{10)}$. Particularly, PFs have special advantages in dealing with non-linear systems. Among the various PFs, sequential importance resampling (SIR) is introduced in this study ${ }^{9}$.

In general, PFs require a number of particles for estimation and prediction, which sometimes causes equifinality problems. Kim et $a l^{7)}$ introduced the reduction factor and the variance tuition factor into the perturbation step to reduce the effect of the equifinality problems which are induced by the interaction of the variables(e.g., discharge and Manning's $n$ ) when utilizing the water level data as reference data. The perturbation step consists of two steps: one is at the initial stage and another is at the updating stage. At the initial stage, the perturbation equations for each variable are as below:

$$
\begin{gathered}
H_{t}^{i, d \text { down }}=H_{t}^{\text {obs,down }}+\varepsilon_{t}, \quad \varepsilon_{t} \sim \mathrm{U}(-0.1,0.1) \\
Q_{t}^{i, \text { in }}=Q_{t}^{\text {hydr }, \text { in }}+\varepsilon_{t}, \quad \varepsilon_{t} \sim \mathrm{U}\left(0.7 Q_{t}^{\text {obs, in }}, 1.3 Q_{t}^{\text {obs, in }}\right) \\
n_{t}^{i, \text { main }}=\varepsilon_{t}, \quad \varepsilon_{t} \sim \mathrm{U}(\alpha, \beta)
\end{gathered}
$$

where $\mathrm{U}$ indicates uniform distribution; $H_{t}^{i, d o w n}$ and $H_{t}^{\text {obs,down }}$ are the downstream water level of each particle and the observed water level at downstream, respectively; $Q_{t}^{i, \text { in }}$ and $Q_{t}^{\text {hydro, in }}$ are the upstream discharge of particle $i$ and the discharge obtained from a hydrological model, respectively; $n_{t}^{i, \text { main }}$ is the Manning's $n$ of particle $i$ at time $t$ for the main channel; and $\alpha$ and $\beta$ are determined by 0.02 to $0.06,0.02$ to 0.08 , and 0.04 to 0.1 to the main channel, flood plain, and inundation area, respectively.

At the updating stage the perturbation equations for each variable are as follows:

$$
\begin{aligned}
& H_{t+1}^{i, \text { down }}=H_{t+1}^{\text {obs,down }}+\varepsilon_{t+1}, \varepsilon_{t+1} \sim \mathrm{N}\left(0,0.1^{2}\right)
\end{aligned}
$$

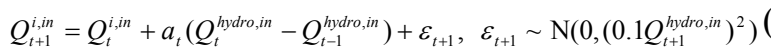

$$
\begin{aligned}
& n_{t+1}^{i}=n_{t}^{i, \text { main }}+\varepsilon_{t+1}, \varepsilon_{t+1} \sim \mathrm{N}\left(0, \mathrm{~s}^{2} \operatorname{Var}_{t}^{n, \text { main }}\right) \\
& \text { in case } \operatorname{Var}^{n, \text { main }}<0.002^{2}, n_{t+1}^{i}=n_{t}^{i, \text { main }}+\varepsilon_{t+1}, \varepsilon_{t+1} \sim \mathrm{N}\left(0,0.002^{2}\right)
\end{aligned}
$$

where $\mathrm{N}$ indicate normal distribution; $a_{t}$ is the recursive correction factor, which is determined by 


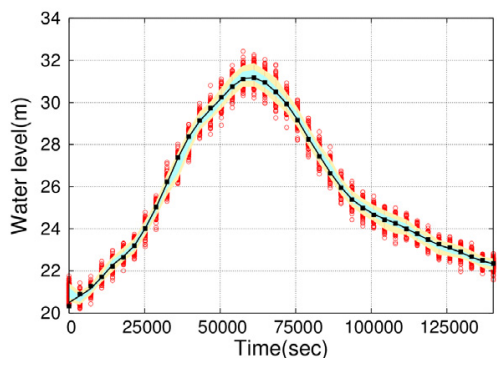

(a) EV_2003(1)

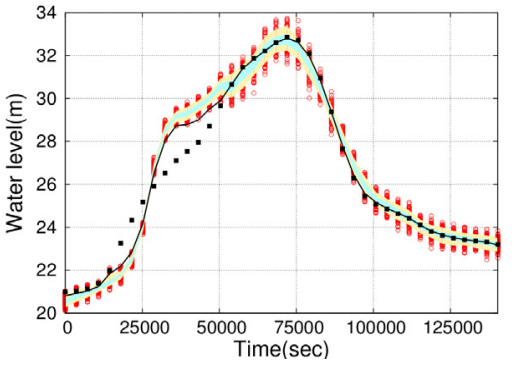

(b) EV_2004A(2)

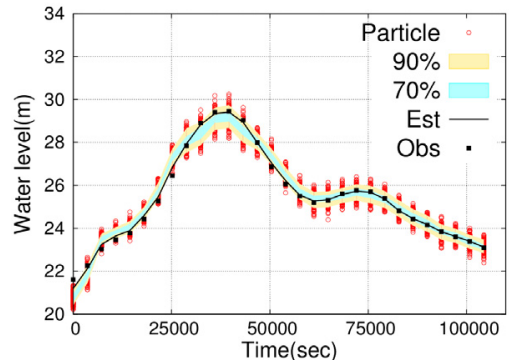

(c) EV_2004B(3)

Fig. 3 The comparison between the estimated water level and the observed water level at upstream.

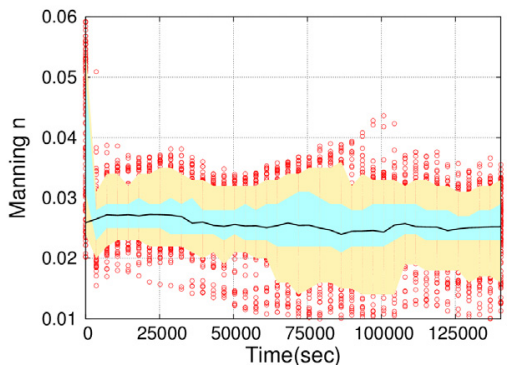

(a) EV_2003(1)

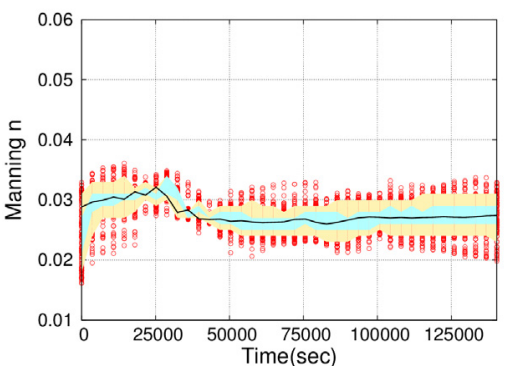

(b) EV_2004A(2)

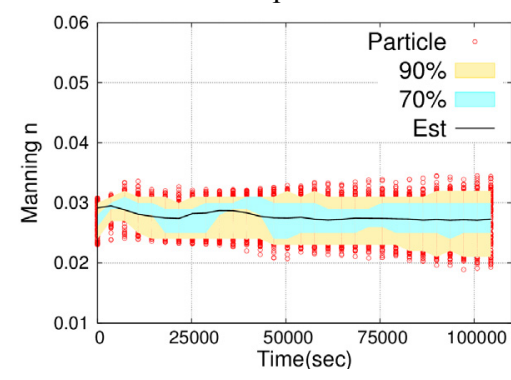

(c) EV_2004B(3)

Fig. 4 The estimated Manning's $n$ at the main channel.

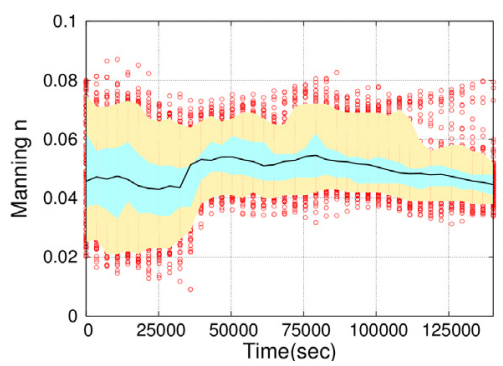

(a) EV_2003(1)

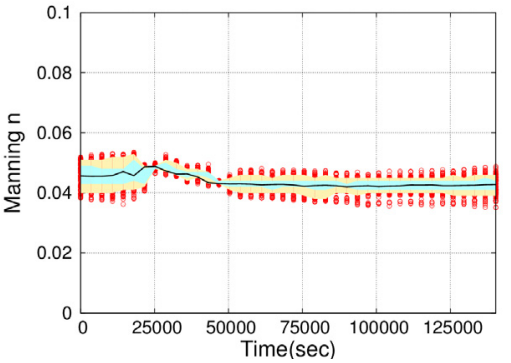

(b) EV_2004A(2)

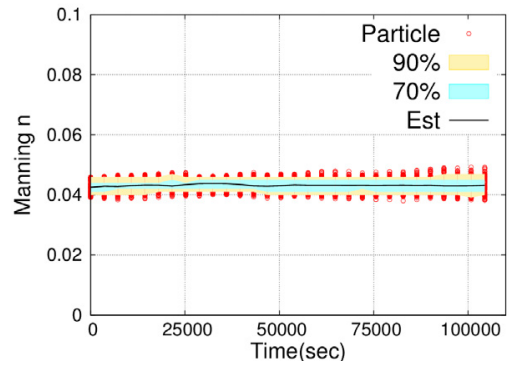

(c) EV_2004B(3)

Fig. 5 The estimated Manning's $n$ at the flood plain.

$a_{t}=\left(\widehat{Q}_{t-1}^{\text {in }} / Q_{t-1}^{\text {hydro, in }}+\widehat{Q}_{t}^{\text {in }} / Q_{t}^{\text {hydro, in }}\right) / 2 ; \quad \mathrm{s}$ is the tuition factor for the variance reduction proposed by Moradkhani et al. ${ }^{11)}$; and $\operatorname{Var}_{t}{ }^{\text {n,main }}$ is the variance calculated at the current step for the weight averaged values.

In case that $\operatorname{Var}_{t}^{n \text {,main }}$ is smaller than the $0.002^{2}$, Eq. (10) is applied to maintain the minimum tracking ability and to consider the change of Manning's $n$ as the channel evolves. In addition, the same equation is applied to the flood plain and inundation area. Manning's $n$ for the specific area is excluded from the filtering target when the number of wetted grids is smaller than $10 \%$ of the number of total grids of each classified zone.

At the resampling step, the likelihood of each particle against the observed water stage is calculated using the Gaussian function:

$$
w_{t}^{i}=p\left(h_{t}^{o b s} \mid h_{t}^{i}\right)=\frac{1}{\sigma \sqrt{2 \pi}} e^{\frac{-\left(h_{t}^{i}-h_{t}^{o b s}\right)^{2}}{2 \sigma^{2}}}
$$

where $w_{t}^{i}$ indicates the likelihood of the $i$ th particle at time $t ; \sigma$ is the standard deviation associated with the observed stage $\left(h_{t}^{o b s}\right)$ and determined by $0.2 \mathrm{~m}$; and $h_{t}^{i}$ is the simulated water stage in each particle.

Then, the normalized weight $\left(_{W_{t}}\right)$ is calculated by the likelihood as follows:

$$
W_{t}^{i}=\frac{w_{t}^{i}}{\sum_{i=1}^{N} w_{t}^{i}}
$$

\section{(4) Estimation results}

For the purpose of identifying the channel roughness of the river channel, the method was applied sequentially to the flood events in August 2003, August 2004, and September 2004. Through the sequential applications with 120 particles, Manning's $n$ is continuously quantified. Figs. 3, 4 and 5 show estimated upstream water levels and Manning's $n$ for the main channel and flood plain, respectively. Figures (a), (b), and (c) in each graph indicate the events occurring in August 2003, August 2004, and September 2004, respectively. In each figure, the cyan and the yellow color area indicate the 70\% and $90 \%$ intervals of the particles. The black line means weight averaged values, and red points indicate the value of each particle. The black points in Fig. 3 are the observed water level used for reference data in the 
estimation process to calculate the weight of each particle. The estimated water level follows the observed water level as the process progresses as shown in Fig. 3.

In terms of Manning's $n$, the initial range at main channel, flood plain and inundation area is set at 0.02 to $0.06,0.02$ to 0.08 and 0.04 to 0.1 , respectively. From the second application, the initial range of Manning's $n$ is set by the $90 \%$ interval of the final step in the previous application (Fig. 4 and 5). As shown in Fig. 4 and 5, the variation of Manning's $n$ is continuously reduced, but the minimum errors are maintained to keep the tracking ability. In addition, the estimated Manning's $n$ for each section shows good agreement with the values reported by $\mathrm{Chow}^{12)}$ and DEFRA/EA ${ }^{13)}$.

\section{ESTIMATIING 2011 FLOOD DISCHARGE}

The method shown in Fig. 1 is applied to estimate the discharge of the event occurring in September, 2011. The observed water level at upstream exists until 5 am on September 3, which is roughly 24 hours before flood peak. Then the water level at upstream exceeds the measurable range of the station. Therefore the estimation process is proceeding by the method proposed by Kim et al. ${ }^{7)}$ before 5am on September 3. The initial range of Manning's $n$ is set by the values, which are 0.021 0.033,0.040 0.047, and 0.057 0.08 at the main channel, flood plain, and inundation area, respectively, from the previous analysis process. After 6 am on September 3, there is no reference data, so the weight of each particle is fixed by the values at the last time step of the update estimation, and is maintained for the subsequent simulation.

In terms of an upstream boundary condition, an averaged hydrograph for the main channel and the tributary (the Akagi River) from the hydrological model with different optimized model parameters ${ }^{1)}$ are considered. The difference between each hydrograph is smaller than $15 \%$ of the given discharge at each time step.

The estimated discharge at the Ouga station is plotted in Fig. 6. The updating procedure is implemented in the section where the percentile interval is located. For the verification of the peak discharge in 2011 flood, we utilized the observed flood marks provided by Wakayama prefecture. The flood marks are compared with the highest water level in each particle of the estimation process in Fig. 7. As shown in Fig. 7, almost all of the flood marks are within the lower parts of the highest water level of particles. This tendency is induced by the effect of the hydrological model outputs because there is a limitation to predicting discharge uncertainties from the time without updating. The level of flood marks at the Hitari station is about $41.4 \mathrm{~m}$, and the particles including the highest water level within $0.5 \mathrm{~m}$ from $41.4 \mathrm{~m}$ are tracked. From the corresponding particles,

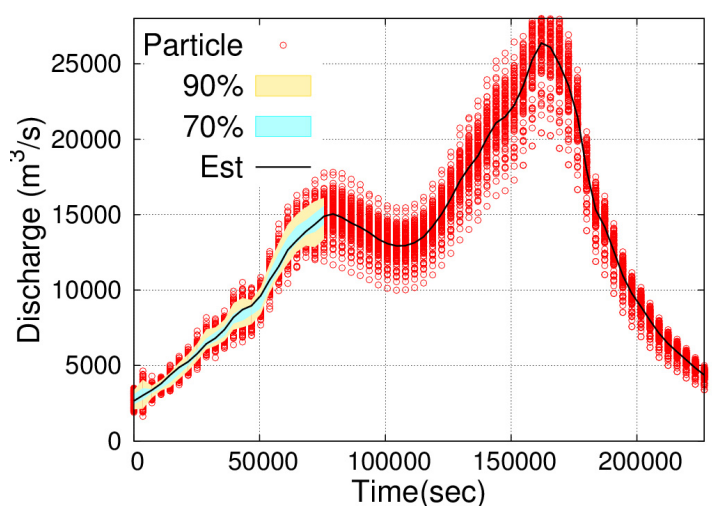

Fig. 6 Discharge estimated from the estimation process at the Ouga station.

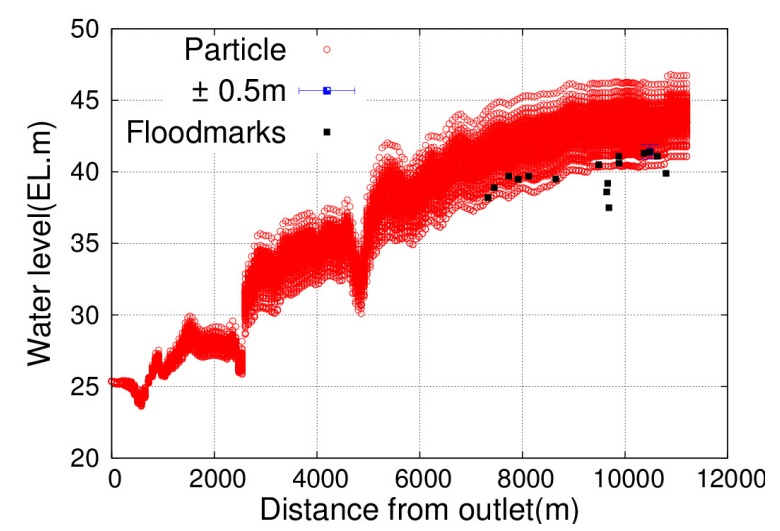

Fig. 7 Comparison between the flood marks and the highest water level estimated from the estimation method.

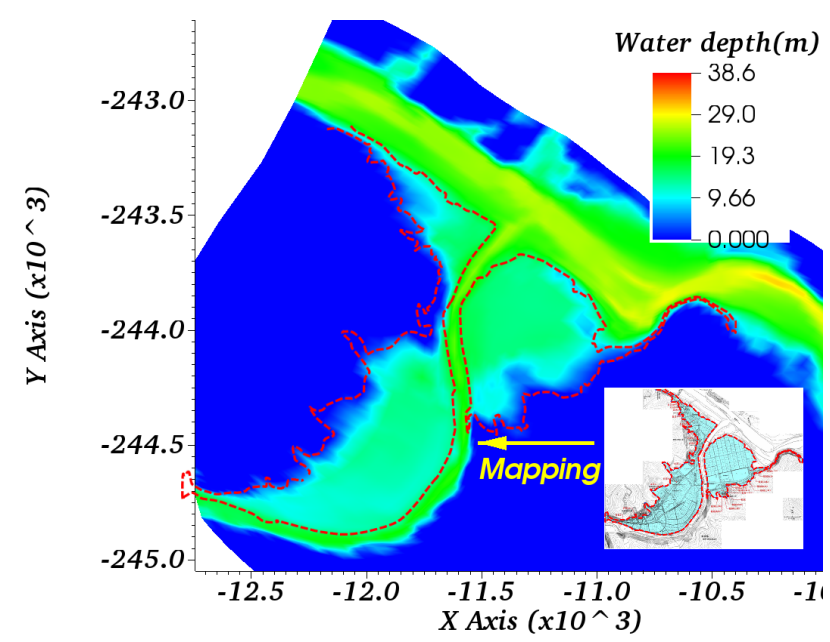

Fig. 8 Comparison of an inundation area, which is the upper part of the study area(as shown in Fig. 2 by a blue line) and is marked by a red broken line to compare a simulated inundation area with an observed inundation area(bottom right).

the peak discharge at the Ouga station is estimated in the range from $22,500 \mathrm{~m}^{3} / \mathrm{s}$ to $25,500 \mathrm{~m}^{3} / \mathrm{s}$ when considering errors by $\pm 0.5 \mathrm{~m}$ from the flood marks (Fig. 6 and 7). Then the inundation areas estimated by the 2D hydraulic model to have the highest water surface profile similar with flood marks in Fig. 7 are compared with the inundation map provided by Wakayama prefecture. The red broken line indicates the inundation area, and it shows good agreement with the simulated results (Fig. 8). 


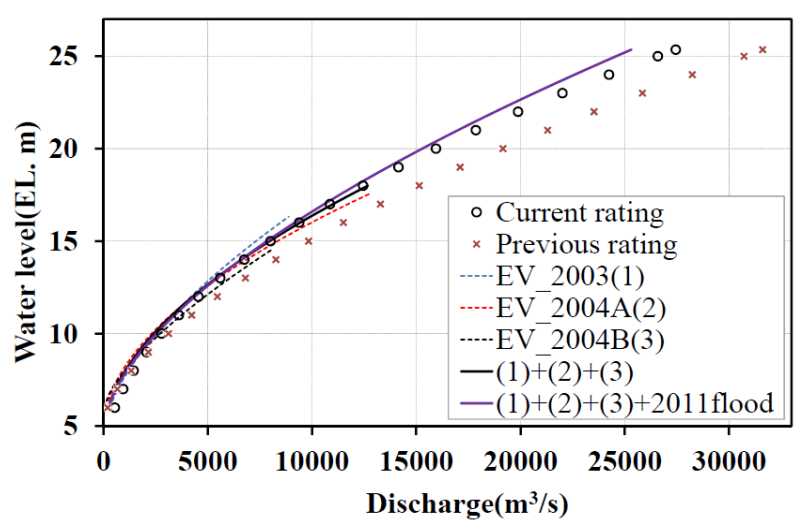

Fig. 9 Comparison between an established rating curve and the existing rating curve at the Ouga station.

In addition, the discharge estimated from the estimation process and the observed water level at downstream are utilized to examine the rating curve at Ouga station. The rating curve is treated as the following power function:

$$
Q=c(a+h)^{\alpha}
$$

where $c$ and $a$ are the constants, and $\alpha$ is an exponent. They define the unique relation between discharge and water level of the open channel.

The rating curves ((1), (2) and (3) in Fig. 9) are established from the estimated results of the three events. Then the rating curve considering the estimated results of 2011 flood and the three events, the old rating curve and the current rating curve developed by MLIT are compared. Through the comparison, it is confirmed that the rating curve established from the estimated results is similar to the currently used rating curve. It shows that sequential applications of the estimation process are able to establish a rating curve comparable with the current rating curve. Using the established rating curve and the observed water level, the peak discharge at the Ouga station is estimated by about $25,300 \mathrm{~m}^{3} / \mathrm{s}$.

\section{CONCLUSION}

An estimation method using a 2D dynamic wave model and particles filters is introduced to estimate the discharge of the event occurring in September, 2011. Before estimating the discharge of the event, the uncertainties of the channel roughness for the main channel, flood plain, and inundation area are quantified by the sequential application of the method. With the quantified channel roughness, inflow to the upper boundary is also estimated from distributed hydrological model outputs. The discharge of the largest event is estimated by considering the uncertainties of roughness coefficients and upper boundary inflows. For the verification of the peak discharge, the highest water level of each particle is compared with flood marks. By the comparison to the flood marks, the peak discharge is estimated in the range from $22,500 \mathrm{~m}^{3} / \mathrm{s}$ to $25,500 \mathrm{~m}^{3} / \mathrm{s}$. In addition, the rating curve established from the estimation process is compared to the currently updated rating curve.

In further research, the estimation process would be combined with a hydrological model to improve the predictability of the water stage and the uncertainties of the hydrologic parameters.

\section{ACKNOWLEDGEMENT}

This works is based on data from Wakayama prefecture and J-POWER CO. Ltd. We gratefully acknowledge this support.

\section{REFERENCES}

1) Meno, T., Tachikawa, Y., Kim, S., Shiiba, M., Yorozu, K., : Analysus of the Kumano river flood by the Typhoon 12, 2011, Proc. of the $67^{\text {th }}$ Annual Conference of the JSCE, II -160, 2012.

2) Tachikawa, Y., Sudo, J., Shiiba, M., Yorouzu, K., and Kim, S.: Development of a real-time rivers stage forecasting method using particle filter, Annual Journal of Hydraulic Engineering, JSCE, Vol.55, pp. S_511-S_516, 2011.

3) Kim, Y., Tachikawa, Y., Kim, S., Shiiba, M., Yorozu, K. and Noh, S.J.: Short term prediction of water level and discharge using a 2D dynamic wave model with particle filters, Journal of Japan Society of Civil Engineering, JSCE, 68(4), pp. I_25-I_30, 2012.

4) Hsu, M.H., Fu, J.C., and Liu, W.C.: Dynamic routing model with real time roughness updating for flood forecasting, Journal of Hydraulic Engineering, 132, pp.605-619, 2006.

5) Ding, Y., Jia, Y., Wang, S.S.Y.: Identification of Manning's roughness coefficients in shallow water flows, Journal of Hydraulic Engineering, ASCE, 130( 6), pp. 501-510, 2004.

6) Kim, W., Kim, Y.S. and Woo, H.Y.: Estimation of channel roughness coefficients in the Han River using unsteady flow model, Journal of Korea Water Resources Association, KWRA, 28(6), pp. 133-146, 1995.

7) Kim, Y., Tachikawa, Y. Shiiba, M., Kim, S., Noh, S.J.: (In press) Simultaeneous estimation of inflow and channel roughness using 2D hydraulic model and particle filters. Journal of flood risk management, accepted in 2012.

8) Nagata, T.: Hydraulics formulae: Hydraulics worked examples with CD-ROM, Hydraulic committee, JSCE, pp.16-19, 2002.

9) Ristic, B., Arulampalam, S., and Gordon, N.: Beyond the Kalman Filter, Artech House, pp. 35-65, 2004.

10) Ioannis Rekleitis.: A Particle Filter Tutorial for Mobile Robot Localization. Technical Report TR-CIM-04-02, Centre for Intelligent Machines, McGill University, Montreal, Quebec, Canada, 2004.

11) Moradkhani, H., Hsu, K. L. and Sorooshian, S.: Uncertainty assessment of hydrologic model states and parameters, Sequential data assimilation using the particle filter, Water Resour.Res., Vol.41, W05012, doi:10.1029/2004WR00364, 2005.

12) Chow, V. T.: Open-channel hydraulics, New York, McGrawHill Book Co. 1959.

13) DEFRA/EA.: Reducing uncertainty in river flood conveyance, Roughness Review, R\&D Technical Report to DEFRA / Environment Agency, Project W5A- 057, HR Wallingford Ltd., United Kingdom, pp. 144-147, 2003.

(Received September 30, 2012) 